

\title{
Design and Testing of Wood Containers for Radioactive Waste
}

\author{
R. S. Roberts \\ P. E. Barry
}

Manuscript date: March 25, 1981

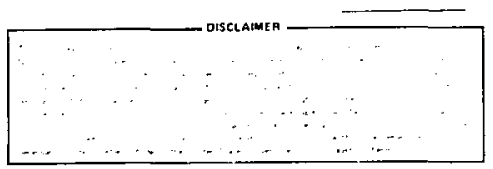

\section{L.AWRENCE LIVERMORE LABORATORY University of California - Livermore, California - 94550}




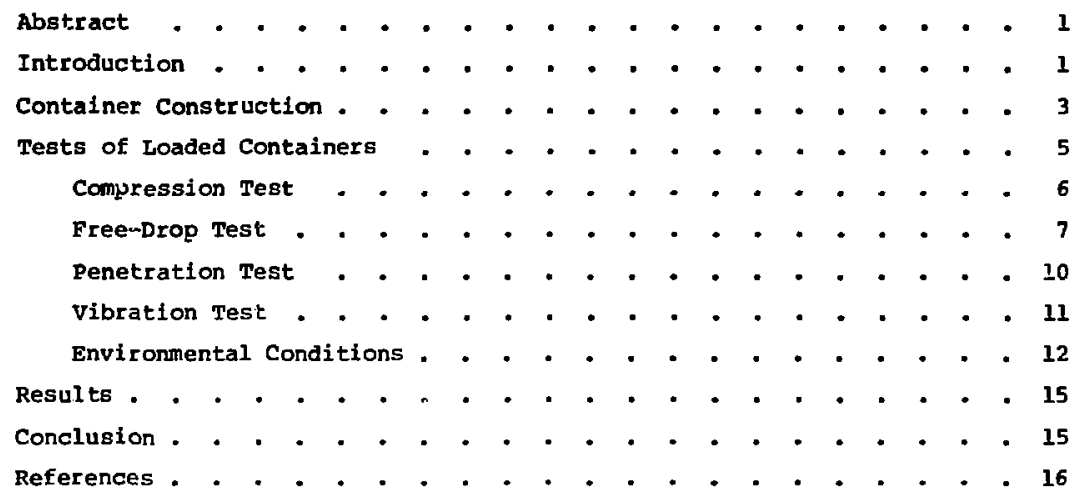


DBSIGN NND TESTING OF

WOOD CONTAMTERS

FOR RADIOACTIVE WASTE

\begin{abstract}
A wood container for shipping and storing radioactive waste was designed to eliminate the problems caused by the welght, cost, and shape of the steel containers previously used. Tests specified by federal regulations (compression, free-drop, penetration, and vibration) were conducted on two of the containers, one soaded to $2500 \mathrm{lb}$ and one loaded to 5000 $1 \mathrm{~b}$. The 5000-1b container failed tha free-drop teat, but the 2500-1b container essily passed the tests and therefore qualifies as a "Type $A$ " container. Its simplicity of design, low weight, and ease in handling have proved to be time-saving and cost-effective.
\end{abstract}

\title{
RNTRODUCTION
}

Thr: Lawrence Livermore National Laboratory (LLNL), at the east end of the Livermore valley in Alamida County, California, is a research institution operated for the Department of Energy by the University of California. The primary purposes of the Laboratory are nucleat weapons research and the development of alternate energy sources. During this research solid hazardous wastes, both radioactive and nonradioactive, are generated. The approximately 8000 cubic feet of radioactive waste sent for disposal each year must be handled, processed, packaged, and shipped according to EPA, DOT, and DOE specifications for "Type $A$ " packaging. These requirements are documented under Title 49, "Transportation," of the Code of Federal Regulations (CFR), paragraph 173.398, "Special Tests." The standards state that Type A packaging must be so designed and constructed that, if it were subject to certain environmental and test conditions,

- There would be no release of radioactive material from the package.

- The effectiveness of the package would not be substantially reduced. 
- There would be no mixture of gases or vapors in the package which could, through any credible increase of pressure or an explosion, significantly reduce the effectiveness of the package.

The prescribed testis are:

- Compression: For packages of not more than 10,000 lb gross weight, the package shall withstand a compressive load equal to five times the weight of the package applied for a period of 24 hours (173.398(b).38).

- Free drop: The package must withstand a free drop through a distance of 4 ft onto a flat, essentially unyielding horizontal surface, striking the surface in a position for which maximum damage is expected (173.398(b)3ii).

- Penetration: The exposed surface of the package which is expected to be most vulnerable to puncture shall withstand the impact of the hemispherical end of a vertical steel cylinder, 1.25 in. in dian and weighing $131 \mathrm{~b}$, falling from a height of 40 in. $(173.398$ (b)iv).

- vibration: The container must withstand any vibration normally incident to transportation $(173.398(b) 2 i v)$.

Environmental conditions are considered in the tests: heat (direct sunlight at ambient temperature of $130 \%$ in still air), cold (ambient temperature of $-40^{\circ} \mathrm{F}$ in still air and shade), and reduced pressurs (ambient pressure of $0.5 \mathrm{~atm}$ ).

These tests are intended to simulate accident conditions during highway transportation of hazardous material and static conditions during storage. Typical trucks for shipping the containers have $8-6 i-40-f t 5:$ 7s which are approximately $4 \mathrm{ft}$ above the surface of the road. The drop test from $4 \mathrm{ft}$ onto the container's weakest corner, striking an essentially unyielding surface, simulates the punishment thet a container would receive if it were to fall from a truck during transportation.

The penetration test simulates impact by a projectile (internal or external), which a container might receive during sudden stops or other motions incident to transportation.

The compression test simulates the static load that a container must withstand if placed at the botton of a stack of containers. 
PABLE 1. Volumes, weights, and costs of containers for radioactive waste.

\begin{tabular}{lcccc}
\hline Container & $\begin{array}{c}\text { Volume } \\
\left(\mathrm{m}^{3}\right)\end{array}$ & $\begin{array}{c}\text { Enqty weight } \\
(1 \mathrm{~b})\end{array}$ & $\begin{array}{c}\text { Maximum gross } \\
\text { weight (lb) }\end{array}$ & $\begin{array}{c}\text { Cost } \\
(\$)\end{array}$ \\
\hline Bennett Bucket & 5.6 & 1400 & 7000 & 1500 \\
Steel $(4 \times 4 \times 7 \mathrm{ft})$ & 3.2 & 2525 & 7000 & 2140 \\
Hood $(4 \times 4 \times 7 \mathrm{ft})$ & 3.2 & 500 & 2500 & 400 \\
\hline
\end{tabular}

An earlier container design, the Bennett Bucket, was a cylindrical steel tank $6 \mathrm{ft}$ in diameter and $7 \mathrm{ft}$ tall. All requirements for Type A packaging were considered in this design. It has been discontinued for reasons such as high cost and the fact that cylindrical containers do not stack efficiently for storage or disposal.

A rectangular steel container $(4 \times 4 \times 7 \mathrm{ft})$ was also designed to fulfill Type A packaging requirements. This container is currently being used for special radioactive wastes, such as tritium, that must have containment impervious to gaseous diffusion. A problem in using steel is that the empty container contributes significantly to the gross weight of the load; this severely limits the weight of waste which can be packaged. The need remains for a practical, inexpensive, rectangular container.

We decided to design a wooden container; this report describes its performance when loaded to 2500 and $5000 \mathrm{Ib}$. Its relative volume, empty weight, maximun gross weight, and cost are compared with those of the two previous container designs in Table 1.

\section{CONTAINER CONSTRUCTION}

The containe: is a wood box with outer dimensions of $4 \times 4 \times 7 \mathrm{ft}$; the construction design is shown in Plg. 1. The floor consists of five 2-by-8-in. grade A pine planks connected to three 4-by-4-in. Douglas fir runners with twelvepenny nalls 3.25 in. long. The floor is covered with a sheet of 0.5-in.-thick $\lambda / B$ plywood fastened with 1.75-in.-long 15-gage staples (this size of staple is used throughout). The sides are of $0.75-$ in,-thick $\mathrm{A} / \mathrm{B}$ plywood sheets fastened to a framework of 2-by-4-in. grade $A$ pine with both 


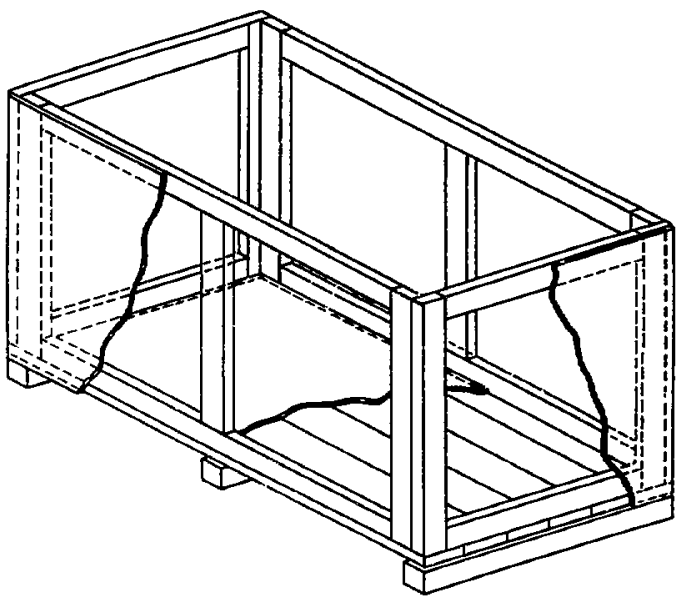

FIG. 1. Cutaway drawing of the wood waste container.

nails and staples. A stapling pattern of 6 in. is used. All joints except the 57 or planks and runners are glued with a special sealant adhesive. The lid is a 0.75-in.-thick plywood sheet glued, nailed, and stapled onto another 2-by-4-in. grade $A$ pine framework. The sides of the box are reinforced by chree 1.25-in.-wide steel bands tightened around the top and bottom edges and the middle. When the box has been filled the lid is glued into place and fastened with staples placed in pairs at intervals of 4-6 in. The box is painted inside and outside with a paint of a composition similar to that of the sealant and white in color, to help it withstand the temperatures it will be subjected to when stored in desert locations (the 2500-1b test container was not painted!. The box is finally reinforced with four $0.75-i n$..wide steel bands tightened around the box from top to bottom.

The ter-polymer sealant used in connecting the joints is a flexible emulsion-type blend of inorganic materials and acrylic polymers. This adhesive was chosen for its strength, superior adhesive properties (to 100 psi for porous surfaces), flexibility (elongation to 5258), and resistance to extremes of weathering and corrosives. A demonstration of the flexibility of the sealant is shown in Fig. 2. When all joints are sealed in this manner, the container's resistance to rigid-shock damage is greatly enhanced.

The simplicity of the construction design has the zdvantage that a large piece of contaminated equipment, for example, can be placed on the finished 
FIG. 2. Flexibility of the ter-polymer sealant used in the wood waste container is demonstrated by radial flexing and folding.

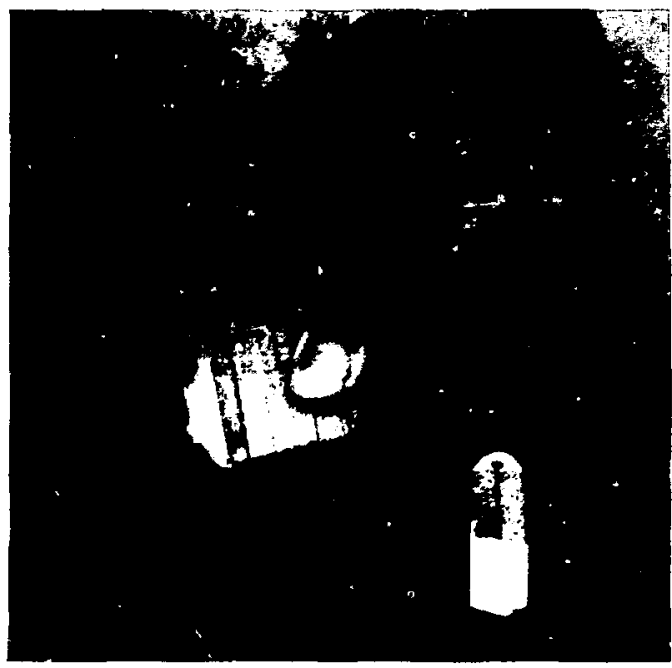

floor of the container and the sides conveniently built around it. This eliminates the often awkward situation of lowering bulky and difficulty manipulated waste into a stable position within the container.

when a container is loaded it can be filled with a urethane foam, if necessary, to prevent shifting of the contents during transportation.

\section{TESTS OF LOADED CONTAINERS}

The materials loaded into the containers to be tested were chosen so as to reach the desired gross weight, completely fill the volume of the containers, and in the event of failure simulate the spilling of contaminated waste. A combination of Drysorb, Portland cement, and Microcel-E (diatomaceous earth) was used. The loading sequence for the containers is shown in Table 2.

The first of the two containers to be tested was loaded to a gross weight of $2500 \mathrm{lb}$. In practice the containers were to be linited to a maximum of that weight. The second container was loaded to a gross weight of $50001 \mathrm{~b}$, 
TABLE 2. Materials used to load the test containers (in sequence).

Material

Amount

Total weight (1b)

Container loaded to

5000 lb gross weight:

Drysorb

30 50-1b bags

1500

Cement

21 94-1b bags

1974

Drysorb

10 50-1b bags

500

Microcell-E

2 50-1b bags

100

Microcel1-E

1 33-1b bag

33

Drysorb

a 50-1b bags

Empty container and lid

500

Total

5007

Container loaded to

2500 ib gross weight:

Drysorb

30 50-1b bags

1500

Microcel-E

8 50-1b bags

400

MicroceI-E

3 33-1b bags

Empty container and lid

which would be considered a worst-case situation berause the container volume would not normally accommodate that much weight.

The compression, Eree-drop, and penetration tests (in that order) were run on each container; these tests were carried out at the Toxic waste control Group's facility at LLN!. The vibration test was run on the 2500-lb container by transporting it from LLNL to the Nevada Test Site (NTS).

\section{COMPRESSION TESTT}

For the compression test, a 660-1b metal plate was first placed on the Iid of each loaded container. The puipose of this plate was to contribute to a part of the total compressive weight (five times the total gross weight) and to distribute the weight uniformly across the top of the containers. The balance of the weight was made up by two pieces of steel armor plate for the 
container loaded to $5000 \mathrm{lb}$, and by a loaded steel waste container for the container loaded to $2500 \mathrm{lb}$. The weights used for the compression tests are shown in Table 3 .

The containers with the weights in place are shown in Figs. 3 and 4 . For the duraticn of the compression test neither container showed any distortion or visible change in configuration.

TABLE 3. Weights used for compression test.

\begin{tabular}{lr}
\hline Item & Weight (lb) \\
\hline $\begin{array}{l}\text { Container loaded to } \\
5000 \text { lb gross weight: }\end{array}$ \\
Metal plate \\
Armor plate (lower) \\
Armor plate (upper) \\
Total & 18540 \\
& 5960 \\
Container loaded to & 25160 \\
2500 lb gross weight: & 660 \\
Metal plate & 12240 \\
waste container & 12900 \\
Total & \\
\hline
\end{tabular}

FREE-DROP TEST

The free-drop test for the container loaded to $2500 \mathrm{lb}$ was done in a high-bay facility with the use of an overhead crane. The crane is not rated to handle a load of $5000 \mathrm{lb}$, so that container was taken outside and elevated with a fork-lift truck.

Each of the loaded containers was elevated to a height of $4 \mathrm{ft}$ and then relsased by means of a quick-release shackle. The containers were elevated in a position so that when dropped the inpact would be on a corner where the lid is attached. (The top corner of a container, because of $i$ ts construction design, is considered to be its most vulnerable point.) The containers were dropped onto a metal plate; the meral plate satisfies the condition that a container strike a flat, essentially unyielding surface. 


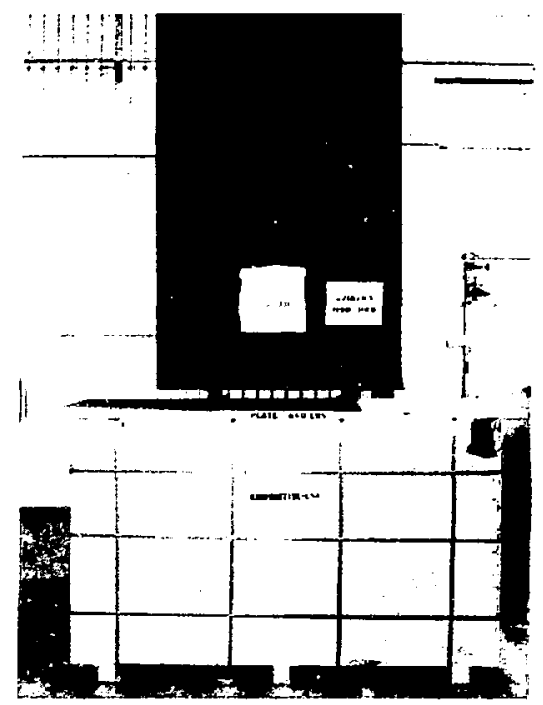

FIG. 3. Container loaded to $2500 \mathrm{lb}$ vith weights in place for the conpression test.

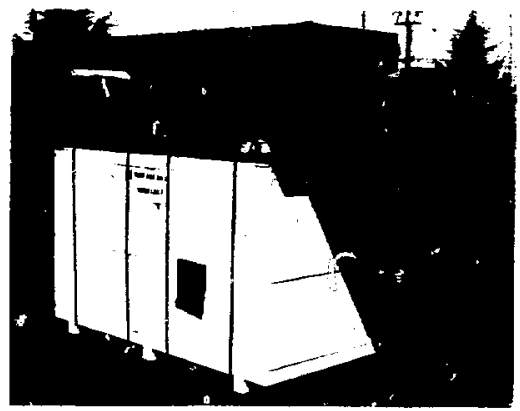

FIG. 4. Container loaded to 5000 1D with weights in place for the compression test. 
The 5000-1b container is shown elevated in position above the meta: plate in Fig. 5, and imediately after impact in Fig. 6. The plywood top ruptured, splintering and releasing a sall anount of the Drysorb from inside. One of the four 0.75-in.-wide steel bands, near where the container ruptured, snapped upon impact; this probably contributed to the breaching of the container. The staples and the adhesive along the lid held; however, the plywood delaninated and the staples pulled through it yet remained irbedded in the side wall (see Fig. 7). One side of the container cracked on inpact: creating a bulge, but the side held (see Fig. 8).

The container loaded to 2500 J,b survived this test; it sustained sowe damage to a corner but maintained its integrity, as shom in Fig. 9.

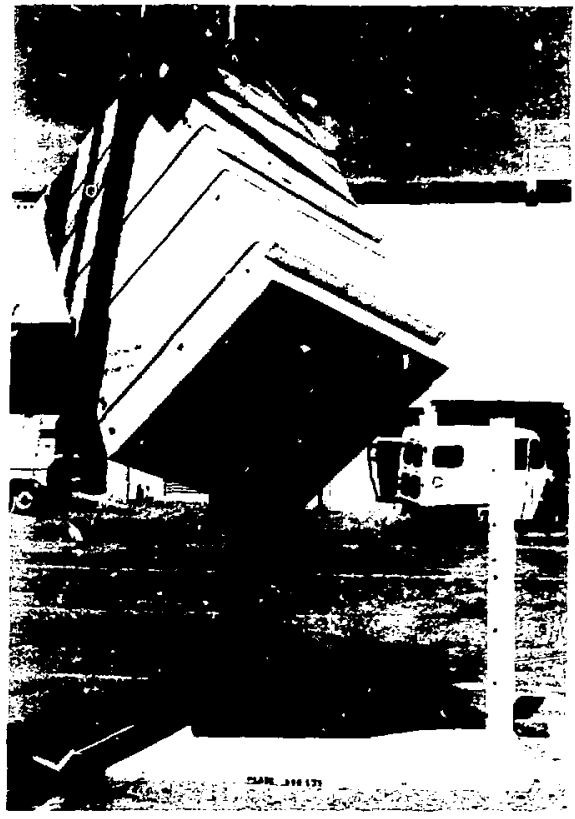

FIG. 5. Container loaderl to $5000 \mathrm{lb}$ in position for the free-drop test, $4 \mathrm{ft}$ above metal plate. 


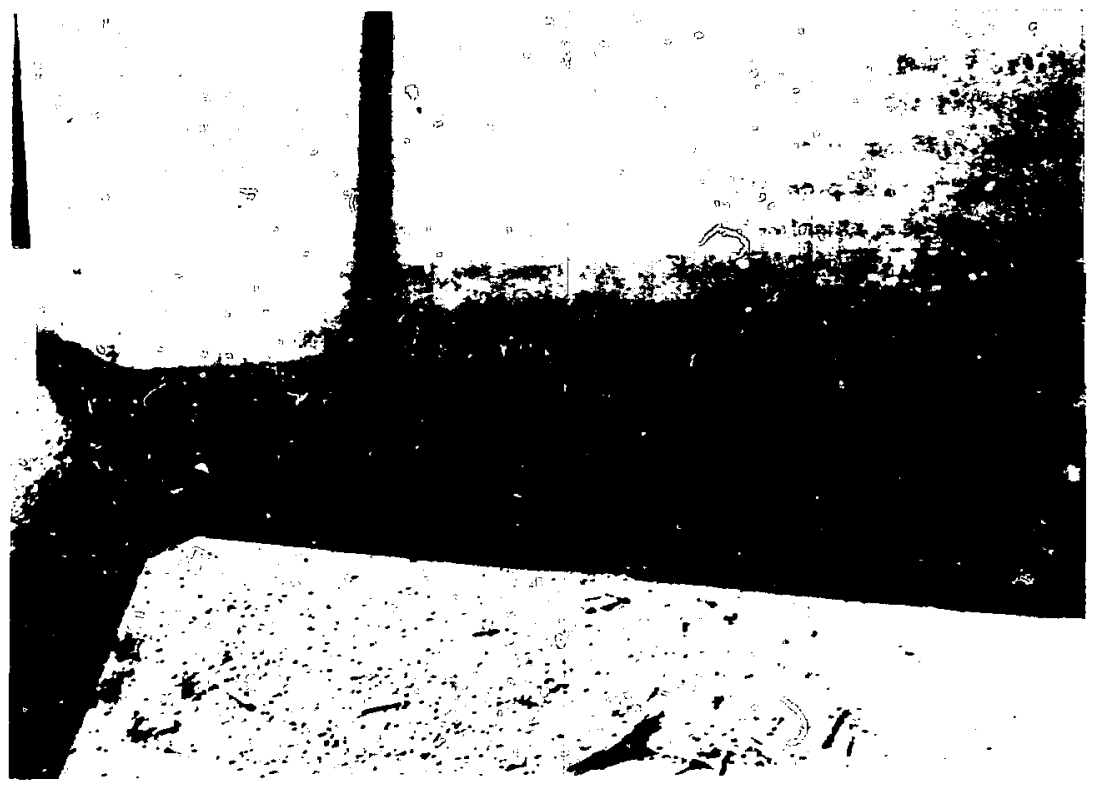

Frs. 6. Container loaded to 5000 lb lying on its top immediately after impact, showing rupture and spilied contents.

PENETRATION TEST

For the penetration test a rod was fabricated to meet the specifications set forth in 49CFR 173.398 (1.25-in. dian and weighing 13 (b). The apparatus for releasing the rod was a length of pipe drilled for the insertion of a pin at several different positions. This pipe was then attached to a stand on which it was elevated vertically above a surface of the container. The rod was then placed in the pipe with the hevispharicai end pointed down, held in place at the desired height with the pin. For the test the pin was quickly removed by pulling on an attached wire, so the rod struck the surface of the container.

The apparatus for performing the test is shown in place, with the steel rod elevated to a height of $40 \mathrm{in.} \mathrm{above} \mathrm{the} \mathrm{5000-1b} \mathrm{container,} \mathrm{in} \mathrm{Fig.} 10$. On

10 


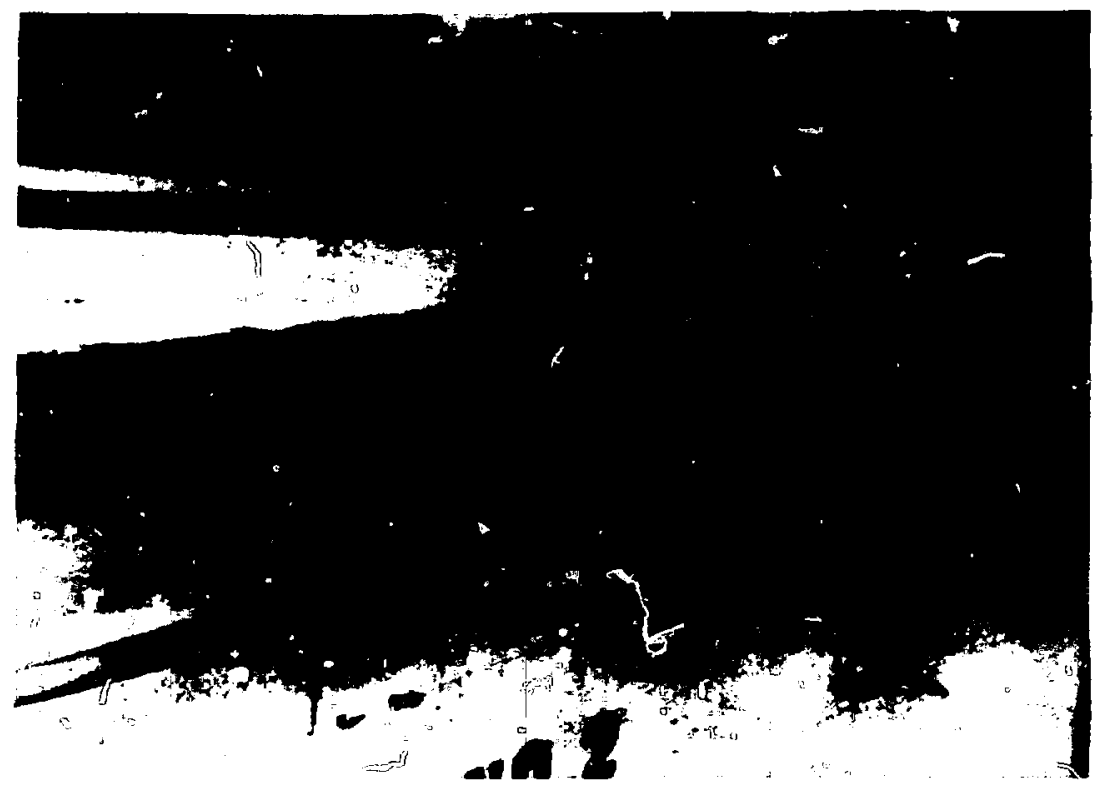

FIG. 7. Rupture of the 5000-1b container, showing delanination of the plywood and the staples having pulled through.

inpact the rod produced a slight indentation about 0.12 in. deep and 1 in. in dian. As expected, the danage was slight.

VIBRATION TEST

Type A containers are transported by IrwL trucks or comon carriers to WIS for burial. When the contalners arrive and are ready to be unloaded and transferred to the burial Eic, they are inspected for evidence of separation and cracking of the seams or other possible dange incident to transportation. The requirements of Type $A$ packaging regarding vibration were aatisfied by observing the 2500-1b container after actual iransportation in an exclusiveuse vehicle to FIS, a distance of $635 \mathrm{ni}$. There was no visible effect of the vibration. No vibration test was run an the container loaded to 5000 lb grose weight. 


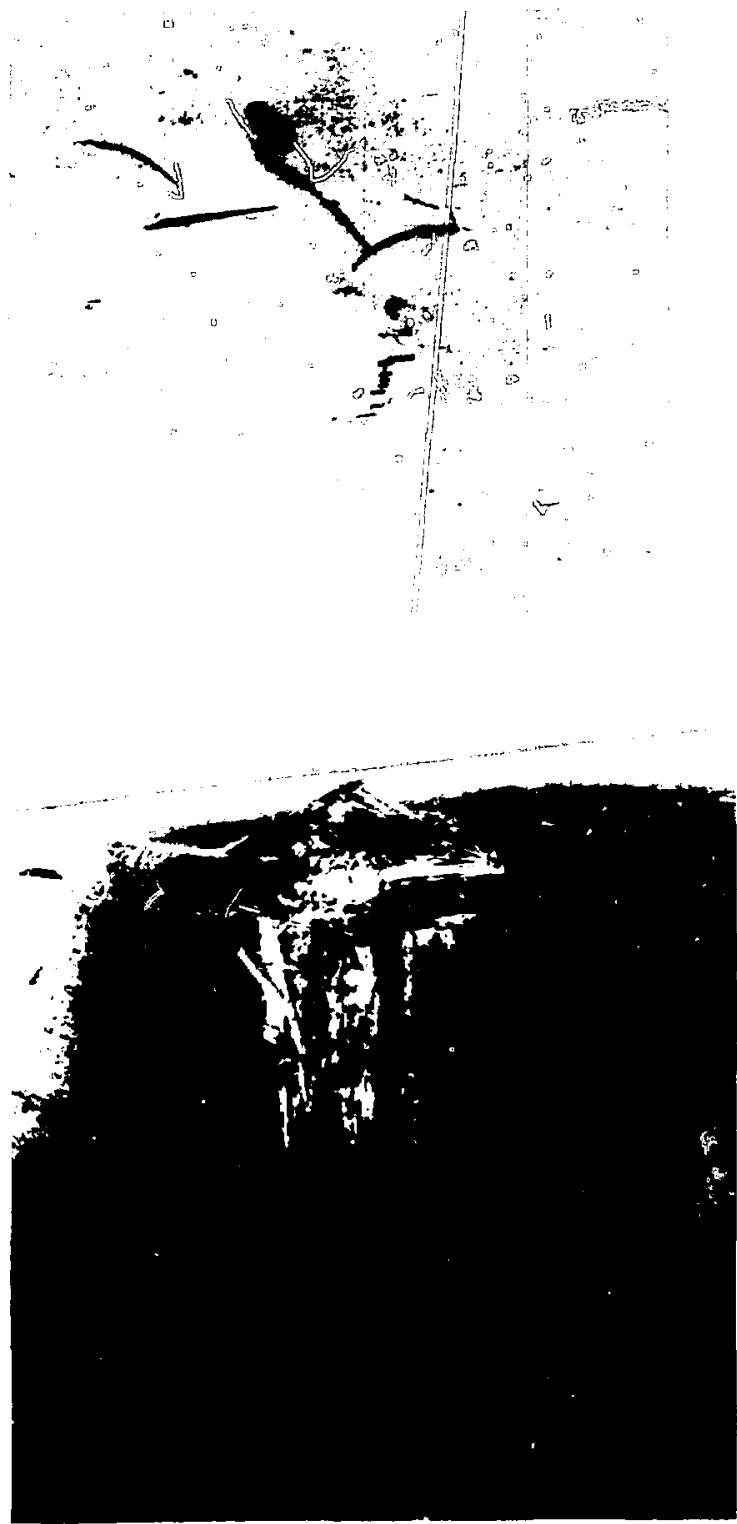

FIG. 8. Bulge at crack on side watl of the 5000-1\% container.

FIG. 9. Damaged corner of the 2500-1b container. 
(After this container design was adopted, a representative shipent of 18 of the containers was sent to Nrs; their weight range was 1411 to 308616 , with an average weight of $2012 \mathrm{lb}$ and a median weight of $1818 \mathrm{lb}$. These containers also did not show any signs of danage resulting fron vibration.)

ENVIRONMENTAI, CONDITIONS

A temperature differential of $170^{\circ} \mathrm{F}$, as specified in the requirements for Type A packaging, coula cause scme container materials to change configuration sufficiently to breach the integrity of the container, releasing radioactive material to the environment. However, the thermal expansion of the resinbonded plywood used in our design is insignificant.

The thermal expansion coefficient for resin-bonded plywood is $4.2 \times 10^{-6}$ per degree Fahrenheit. ${ }^{1}$ This number represents the maximum measured expansion. For the 7-ft side of the container, expansion would be $0.06 \mathrm{in}$. over the temperature differential of $170^{\circ} \mathrm{F}$. For the 4 -ft side it would be 0.03 in. Considering the flexibility of plywood and of the ter-polymer sealant used to seal all of the container seams, this would cause no damage to the container. For Douglas fir, the distortion at the center of the container wall due to a pressure differential of 0.5 atm wold be ${ }^{2}$ :

$$
D_{\max }=\frac{0.1422 \omega b^{4}}{E t^{3}\left(1+2.21 \alpha^{3}\right)}=4.8 \mathrm{in} .
$$

where

$$
\begin{aligned}
& D_{\text {max }}=\text { maximum displacement } \\
& E=\text { modulus of elasticity }\left(1.95 \times 10^{6} \mathrm{lb} / \mathrm{in} .^{2} \text { for Douglas fir }\right) \\
& t=\text { thickness in inches }(0.75 \mathrm{in.}) \\
& w=10 a d \text { in } 1 \mathrm{~b} / \mathrm{in}^{2}\left(7.35 \mathrm{lb} / \mathrm{in.}^{2}\right) \\
& a=84 \mathrm{in.}(7 \mathrm{ft}) \\
& b=48 \mathrm{in} .(4 \mathrm{ft}) \\
& \alpha=\frac{b}{a}(0.57)
\end{aligned}
$$

This severe distortion would occur only under conditions such as the container's being taken to an altitude at which the ambient pressure is 0.5 


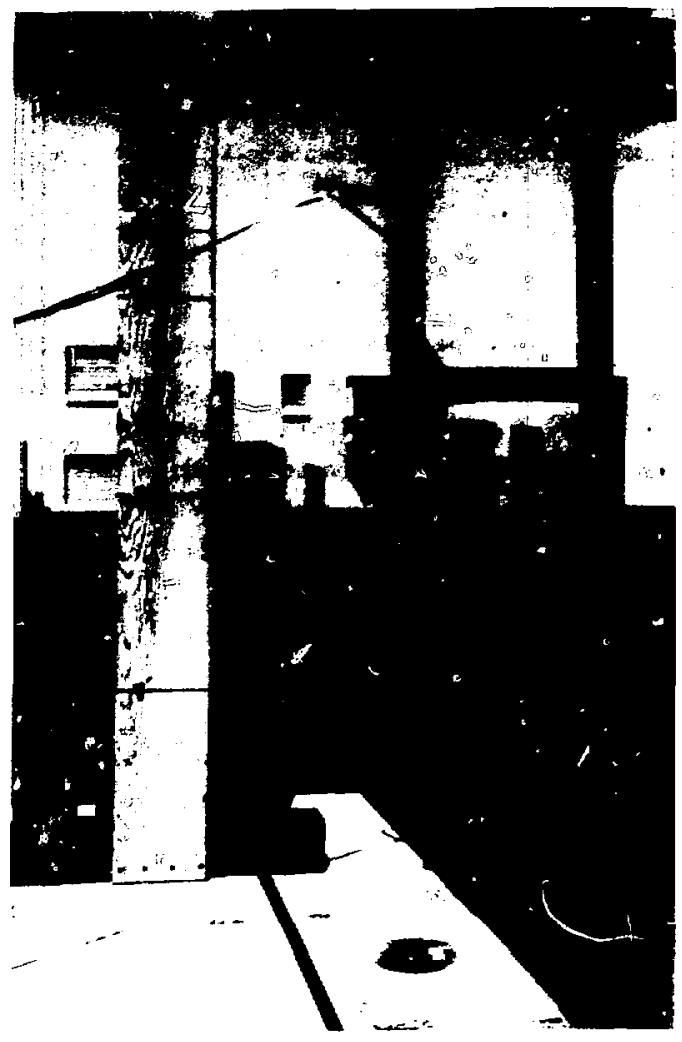

FIG. 10. Steel rod in position for the penetration test, 40 in. above the top of 'he container. 
atm $(4.3 \mathrm{mi}) .^{3}$ A pressure differential on the walls of the container could also develop if a pressurized container such as a gas bottle or aerosol can inside the container were to rupture; however, these are not disposed of in wooden waste containers.

\title{
RESULTS
}

The results of the tests are sumarized below.

\section{Container loaded to 5000 lb gruss weight:}

\author{
Compression test: Passed; no visible effect on the container. \\ Free-drop test: Failed; slight release of the contents of the \\ container (Drysorb) . \\ Penetration test: Passed; very slight damage to the surface. \\ Vibration test: No vibration test was $r$ un on this container, s: nce \\ actual loadirg is limited to a maximum of $2500 \mathrm{lb}$.
}

\section{Container loaded to 2500 lb gross waight:}

Compression test: Passed; no visible effect on the container. Free-drop test: Passed; mininal danage to a corner.

Penetration test: Passed; very slight damage to the surface.

vibration test: Passed; no vinible damage.

\section{CONCLUSION}

The container proved to be simple to assemble and can be built around bulky waste material. It is comparatively light, which increases the net payload, and the simplicity of the design and ease in handling have proved to be timesaving. The materials for construction are readily available and easy to work with. These features ma'se the container cost-effective and practical. It easily meets Type A packaging specifications when limited to 2500 lb total gross weight. At 5000 lb the container performed well, but in our opinion did 
not meet the criteria bet forth in 49CFR paragraph $173.398(b) 1(i)$ : there could be a release of radioactive material from the package at a 5000-1b load. This container has been adopted for TYpe A packaging of LINL radioactive waste for transportation to NTS.

\section{REFERENCES}

1. U.S. Forest Products Jaboratory, U.S. Forest Service, and U.S. Department of Agriculture, Encyclopedia of Wood, No. 72 (Drake Publisher Company, Madison, WI, 1977).

2. J. Roark, Formulas for Stress and Strain (McGraw-Hill Book Company, New York, 1954), 3 rd ed.

3. N. A. Lange, Handbook of Chemistry (McGraw-Hill Book Company, New York, 1972), 1.2 th ed. 